\title{
Intuition in Information Technology Investment Decision: A Quantitative Method
}

\author{
Aris Kusumawati ${ }^{1}$, Apol Pribadi Subriadi ${ }^{1}$
}

\begin{abstract}
IT investment decisions made by the company have uncertain value characteristics; have a high risk than other capital investment failures and intangible benefits of expected. In this situation, effective decision making is an important (perhaps most important) part of managerial activity. In this article, we analyze the influence of decision making under uncertainty, company size, and environmental hostility to intuition and analyze the intuition of company performance. There are five companies as study sample (ie: university, hospital, regional owned enterprises, creative industry, and software house industry) in East Java, Indonesia. The method used was a survey. The respondents were Top Level Management that is responsible for IT investment decision. Data analysis techniques used was Structural Equation ModelingGeneralize Structure Component Analysis (SEM-GSCA). Although intuition process is critical for effective IT investment decision making, we found that: (1) decision making under uncertainty and environmental hostility did not affect on intuition; (2) company size has a positive effect on intuition, and (3) intuition has a positive effect on company performance.
\end{abstract}

Keywords-Uncertainty, Company Size, Environmental Hostility, Gut Feeling, Company Performance, Organizational Behavior, SEM-GSCA.

\section{INTRODUCTION}

In the business environment, formal and rational techniques are sometimes difficult or impossible to do the decision making in Information Technology (IT) Investment. Managers rely more on information-based intuition as they do on rational analysis[1]. Effective managerial decision-making not only rationally analyzes their choices but also uses intuitive judgments to support risk-taking, determining business flow, and leadership style[2]. Therefore intuition should not be ignored, because intuition is a different reasoning that can take into account how actual decisions can be determined not just quantitative data in the database[3]. For many years the research on strategic decision making focused mainly on the rational aspect of the process approach can be described as purely logic and step-by-step: define, diagnose, design, decide[4]. But, the researchers discovered several limits to rationality in decision-making. The effective manager needs to analyze problems systematically and at the same time need to respond to situations rapidly according to intuition and personal judgment. Sometimes decision makers often rely on methods based on "acts of faith" or

\footnotetext{
${ }^{1}$ Aris Kusumawati and Apol Pribadi Subriadi are with Department of Information Systems, Institut Teknologi Sepuluh Nopember, Surabaya, 60111, Indonesia. E-mail: kusumawati.aris@gmail.com; apolpribadi@gmail.com.
}

"acts of faith" - some form of phrases from literature such as "blind faith" or intuition[5]. Based on the explanation, this article provides a study to analyze the importance of the role of intuition in IT investment decision making.

In this article, we review and developed a conceptual model that delineates five key constructs in information technology (IT) investment decision making, ie: decisionmaking under uncertainty, company size, environmental hostility, company performance, and intuition based on the theory of strategic decision making, organization theory, organizational behavior, contingency theory, IT investment and its extensions to interrelate these constructs. The purpose of our conceptual model is to examine the antecedents factors and its consequences of intuition in IT investment decision.

\section{A. Theoretical Model and Hypothesis}

In formulating the new theoretical model conceptually, we highlight some IT investment decision concerns which should be considered in this article, as contained in many relevant theoretical and empirical studies. This theoretical model integrating the literature on the antecedents of intuition and combines factors associated with three perspectives on decision intuition, ie: decision-specific features, company characteristics, and environmental. It also incorporates an outcome variable in strategic decisionmaking, ie: company performance in IT investment.

Intuition is a topic of organizational behavior[6]. Measurement of intuition in this article is done through three operational indicators, ie: a lack of clear information, ambiguity in reliance on judgment, experience, and use of "gut feeling"[7].

\section{1) Decision Making Under Uncertainty}

Intuition may be effective under uncertainty conditions, which is a category of decision-specific characteristics[8]. Some previous research have treated uncertainty conditions as a mystery that can not be resolved by rational processes[9]. In this article, under uncertainty conditions refers to a phenomenon of value in IT investment decision. Top management level is confused about how to measure (or calculate) the value of an IT business. The value of an IT business is more than just financially rewarding. IT business value concepts include how IT delivers efficiency, effectiveness, productivity enhancement, and creates a competitive edge for a particular organization[10]. So that, the investment value of IT organizations today is filled with uncertainty and still a mystery questionable[11].

Measurement of decision making under uncertainty in this article is done through three operational indicators, ie: a 
lack of clear information, ambiguity in analyzing decision options, and difficulty in predicting decision outcomes[10][13]. Based on description effect of decision making under uncertainty conditions and intuitio, we proposed hypothesis 1:

H1: Decision making under uncertainty has an influence on the intuition in IT investment decision.

\section{2) Company Size}

Strategic of organizations and company size have a relationship in the decision-making process[14], [15]. In small organizations, intuition more influential to decisionmaking better than larger organizations[7]. In the larger organization, decision making dependents on formalized approaches to make a decision. But in the small organization, decision-making refers to a single or a few individuals[16].

Measurement of company size in this article is done through two operational indicators, ie: the number of persons employed and net assets[17]-[19]. Based on description effect of company size and intuition, we proposed hypothesis 2 :

H2: Company Size has an influence on the intuition in IT investment decision.

\section{3) Environmental Hostility}

Contingency theory in the environment and strategic management can influence the process of intuition, it produces a final variation of conclusions[20]. In a similar study, the differences in environmental conditions affected the different ways managers dealt with strategic issues and rapidly changing business environment, causing the manager to act quickly as well, therefore the decision process by intuition needs to be used in the organization[21]. In this article, the discussion of environmental impacts is focused on environmental hostility according to some previous research[22].

Measurement of environmental hostility in this article is done through four operational indicators, ie: resource scarcity, restrictiveness, competition, and declining market trends[22]. Based on description effect of environmental hostility and intuition, we proposed hypothesis 3 :

H3: Environmental Hostility has an influence on the intuition in IT investment decision.

\section{4) Company Performance}

Intuition is an emerging topic of interest in organizational behavior[6]. It is connected to the professional experiences of the managers, their personal judgments, and can be experienced as a strong feeling of knowing what will happen[23]. In research on strategic decision-making, some authors investigate company performance[20]. And in a similar study concluded that intuition has a positive effect on organizational performance[7].

Measurement of company performance in this article is done through two operational indicators, ie: operating performance and market-based performance[24]. Based on description effect of company performance and intuition, we proposed hypothesis 4 :

H4: Intuition has an influence on the Company Performance in IT investment decision.
Finally, the theoretical research model to investigate the role of intuition in IT investment decision to measured company performance was proposed with a variableindicator of Decision Making Under Uncertainty, Company Size, Environmental Hostility, Intuition in IT investment decision, and Company Performance, as presented in Figure 1.

\section{METHOD}

Before the survey started, the questionnaire instrument was pre-tested with pilot studies. The survey applied a standardized written questionnaire using Likert scales of 1 (totally disagree) to 5 (totally agree) was used to measure an itemized statement from respondents survey.

\section{A. Population and Sample Description}

The face-to-face survey method was used. The population was focused on organizations that have made IT investment. Convenience sampling is a non-probability sampling technique was used in this article. Samples taken from university, hospital, regional owned enterprises, creative industry, and software house industry was chosen research object. Respondent of this article is managerial which are involved in the process of information technology (IT) investment decision making context.

\section{B. Data Collection and Analysis Techniques}

According to Table 1 "Sample Description", we have collected data questionnaires to 40 respondents to be analyzed within two stages involving two tools: 1) descriptive statistical analyzed with Statistical Package for the Social Sciences (SPSS) for validity, reliability, linearity tests; and 2) inferential analyzed using Generalized Structured Component Analysis (GSCA) because in this article we begin with determining formative and reflective measurement model to be applied in a small sample. GSCA is a new method of SEM-based components that can be used to perform calculations scores and also can be applied to a small sample with formative and reflective indicator construct[7].

\section{RESUlTS AND DISCUSSION}

In order to analyze the data and result, we require conducting reliability and validity tests. This study uses SPSS to conduct the tests. Reliability test is aimed to check the consistency of our survey while validity test is used to ensure that our test or survey correctly measures what we aim to measure. For reliability test, we rely on Cronbach's Alpha to measure how close the relationship between items is. A sample is called reliable when the value of its Cronbach's Alpha is larger than 0.6. As for the validity test, we calculate it based on the correlation between each variable and the total score of the variables, using Pearson Correlation. An item is valid when the value of the correlation contains **.

Linearity relationships assumptions of equation model must fulfilled for GSCA analysis. Testing linearity with 
Curve Fit method shows all relationships between latent variables have significance below $5 \%(\mathrm{p}<0.05)$. It concluded relationship between latent variables in structural model was linear. The path coefficients is an output obtained from GSCA (Table 3).

According to Table 3, all CR values are significant at 0.05 levels. This implies that variables "Decision Making Under Uncertainty to intuition" and "Environmental Hostility to intuition" which used in this study have not a significant influence on each other. Variables "Company Size to intuition" and "Intuition to Company Performance " which used in this study have a significant influence on each other. Variables Company Size to intuition is significant with CR value is 19.52* and Variables Intuition to Company Performance is significant with CR value is 31.75*. Variables Uncertainty to Intuition is not significant with CR value is 1.7 and Environmental Hostility to Intuition is not significant with $C R$ value is 0.74 . In addition to the significant levels, all variables in the path coefficients have positive influence to other related variables, as seen that all their estimate level is positive.

Structural model evaluation was done to determine relationships among latent variables. For models with formative and reflective indicators, examination of goodness of fit model was based on FIT and AFIT value (Table 4 and Figure 2).

Based on the output GSCA in the fitness of model (Table 4 and Figure 2), the identification goodness of FIT is 0.504 . FIT shows the total variance of all the variables that can be explained by a particular model where the values range from 0 to 1 . In this model, it means that the diversity variables consisting of Uncertainty, Company Size, Environmental Hostility, Intuition and Company Performance that can be explained by the model is $50.4 \%$. The remaining $49.6 \%$ can be explained by other variables. Seen from the AFIT value, diversity variables consisting of Uncertainty, Company Size, Environmental Hostility, Intuition and Company Performance that can be explained by the model is $48.5 \%$. The remaining $51.5 \%$ can be explained by other variables. The NPAR value of the model is 21 , which shows the number of free parameters used in the calculation of GSCA tools, including weights, loadings, and path coefficients.

Hypothesis testing was done by looking at the relationships significance between variables, as shown Table 3. If it was significant $\left(\mathrm{CR}^{*}=\right.$ significant at .05 level), the hypothesis was accepted, whereas if it was not significant, the hypothesis was rejected. Thus hypothesis H1 Decision making under uncertainty has an influence on the intuition in IT investment decision was rejected. Hypothesis H2: Company Size has an influence on the intuition in IT investment decision was accepted. Hypothesis H3: Environmental Hostility has an influence on the intuition in IT investment decision was rejected. Hypothesis H4: Intuition has an influence on the Company Performance in IT investment decision.
Hypothesis Testing and Path Coefficients (Table 3) correlation analysis between company size with intuition in IT investment decision, confirming that the company size has a significant effect on intuition. Measurements of company size, where the company size with number of persons employed and net assets, proving the effect of intuition in IT investment decision to contribute a success in company performance. This study confirms some previous research results[3], [14]. And correlation analysis between intuition in IT investment decision with company performance, confirming that the intuition in IT investment decision has a significant effect on company performance. Measurements of intuition in IT investment decision, where the intuition in IT investment decision with Reliance on Judgment, Reliance on experience, and use of "gut feeling" , proving the effect to contribute a success of company performance. This study confirms some previous research results[7], [8].

Correlation analysis between uncertainty to intuition inform that firm uncertainty not significantly affect intuition in IT investment decision and environmental hostility not significantly affect intuition in IT investment decision. Based on these results, this article proves that the correlation between company size with intuition and intuition with company performance can be applied by the decision-maker in the organization as input and trigger to using intuition in IT investment decision.

\section{CONCLUSION}

\section{A. Directions for Future Research}

From our result description and analysis, this article has contributed to academics and practitioners knowledge: 1) intuitive decision-making style at managerial levels theoretical model considering the company size which influences the use of intuition; 2) If financial calculations and formal approaches often collide with assumptions and limitations, intuition gives the role and impact a decision outcome variable, company performance.

\section{B. Limitations and Directions for Future Research}

This article is subject to a number of limitations. First, the sample for this article only uses 40 data to statistic method. Further articles were recommended to uses large sample size to statistic method. Second, our sample was drawn from multiple cases study. Therefore, caution should be expressed in generalizing these findings to minimize the risk of systematic response bias. While our data enjoy a modest level of entering respondent reliability, and many related studies have collected data from a single case study. Third, our theoretical model conceptual and operational scope does not do justice to the full breadth of the contextual variables potentially affecting intuition in IT investment decision. For future research, researchers need also combining another value benefit from IT investment management, characteristic of IT investment, the complexity of IT investment criteria, etc before formulating in the new model using intuition in decision making. 


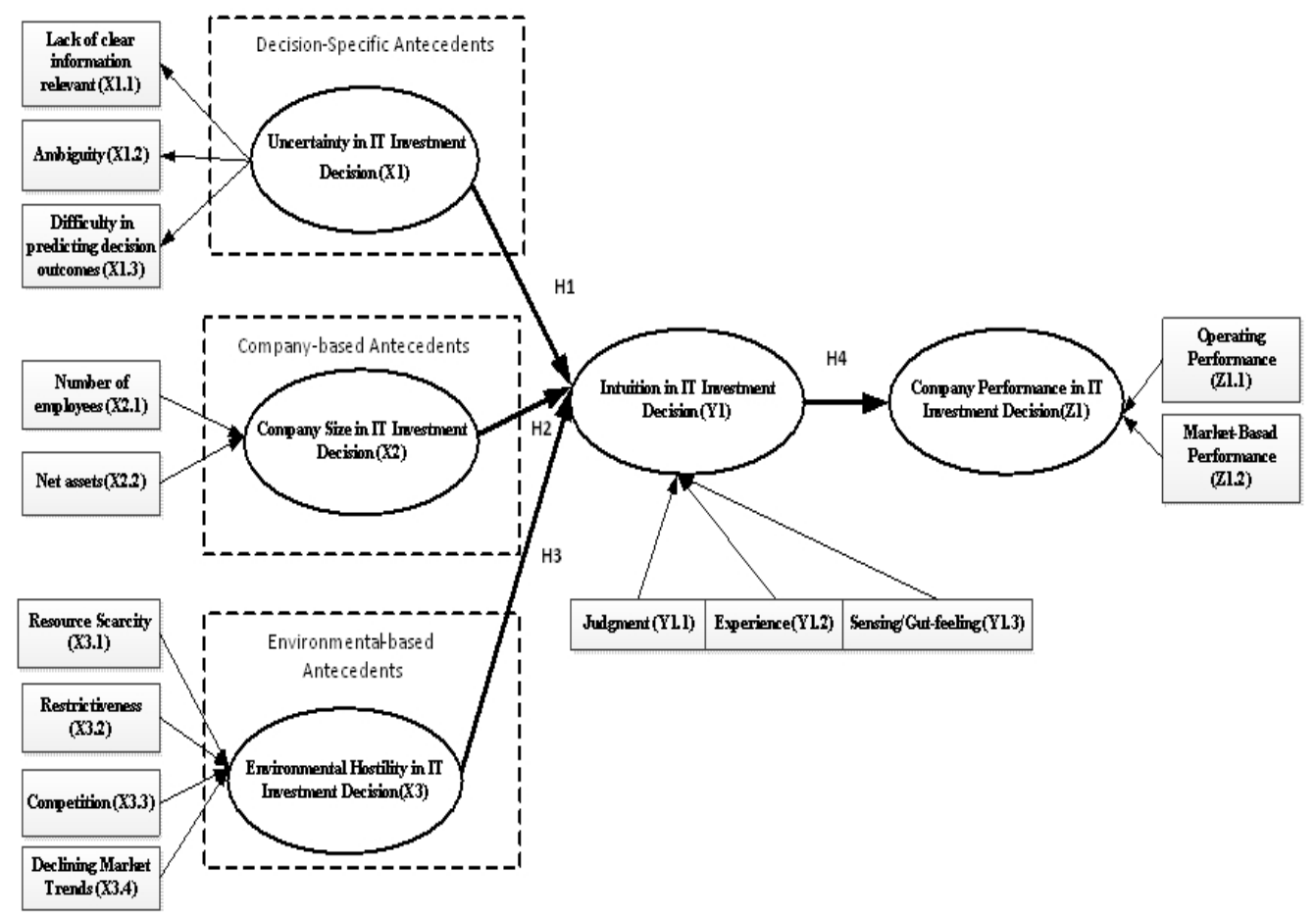

Figure 1. Theoretical Model Conceptual, Operational and Hypothesis.

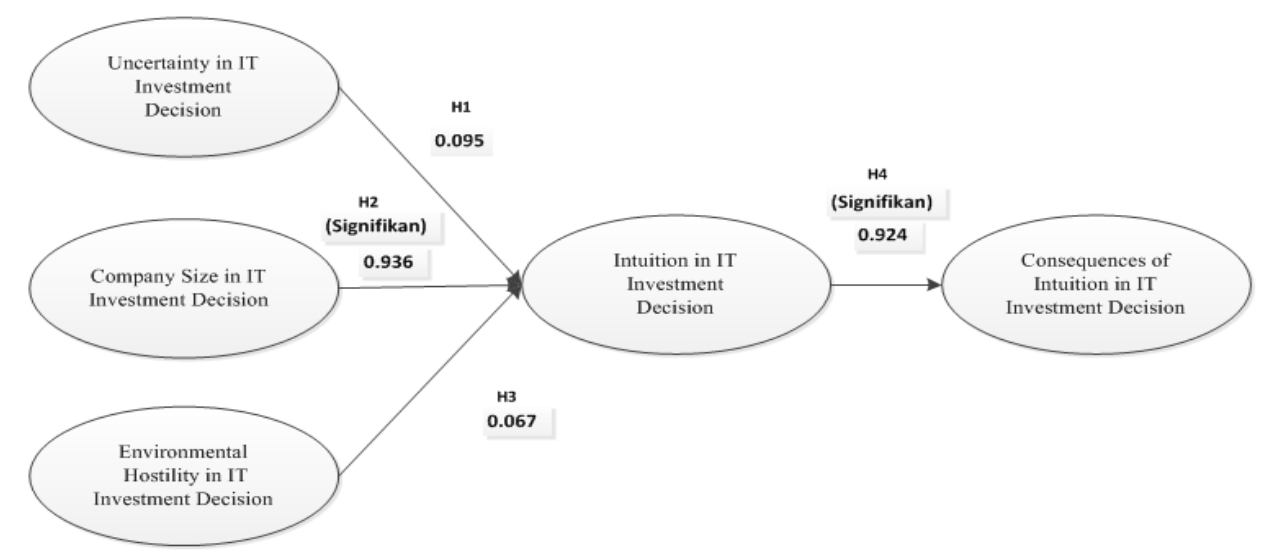

Figure 2. Diagram for Hypothesis Testing and Path Coefficient of GSCA.

TABLE 1.

SAMPLE DESCRIPTION

\begin{tabular}{lcccc}
\hline \hline \multirow{1}{*}{ Samples } & & Respondent & Number of \\
\cline { 2 - 4 } & Top-level management & Middle-level management & Low-level management & Respondents \\
\hline University & 2 & 4 & 1 & 7 \\
Hospital & 4 & 9 & 0 & 13 \\
Regional owned enterprises & 3 & 3 & 4 & 10 \\
Creative industry & 2 & 3 & 1 & 6 \\
Software house industry & 3 & 1 & 0 & 4 \\
Total & & & & 40 \\
\hline \hline
\end{tabular}

TABLE 2.

LINEARITY RELATIONSHIPS

\begin{tabular}{lcc}
\hline \hline \multicolumn{1}{c}{ Variable } & Deviation from Linearity & Significant from Linearity \\
\hline Decision Making Under Uncertainty (X1) -> Intuition (Y1) & .000 & $\sqrt{ }$ \\
Company Size (X2) -> Intuition (Y1) & .000 & $\sqrt{ }$ \\
Environmental Hostility (X3) -> Intuition (Y1) & .000 & $\sqrt{ }$ \\
Intuition (Y1) -> Company Performance (Z1) & .000 & $\sqrt{ }$ \\
\hline \hline
\end{tabular}


TABLE 3.

Hypothesis TESTING AND PATH COEFFICIENTS

\begin{tabular}{lcccccc}
\hline \multirow{2}{*}{ Hypothesis } & \multicolumn{3}{c}{ Path Coefficients } & & \multirow{2}{*}{ Empirical } & Evidence \\
\cline { 2 - 5 } & Estimate & SE & CR & & Rejected \\
\hline Uncertainty->Intuition & 0.095 & 0.056 & 1.7 & Insignificant & Accepted \\
Company Size->Intuition & 0.936 & 0.048 & $19.52^{*}$ & Significant & A \\
Environmental Hostility->Intuition & 0.067 & 0.09 & 0.74 & Insignificant & Rejected \\
Intuition->Company Performance & 0.924 & 0.029 & $31.75^{*}$ & Significant & Accepted \\
\hline \hline CR* = significant at .05 level & & & & & &
\end{tabular}

TABLE 4.

MEASURE OF FIT STRUCTURAL MODEL

\begin{tabular}{cc}
\hline \hline \multicolumn{2}{c}{ Model Fit } \\
\hline FIT & 0.504 \\
AFIT & 0.485 \\
NPAR & 21 \\
\hline \hline
\end{tabular}

\section{REFERENCES}

[1] G. P. Hodgkinson, E. Sadler-Smith, L. A. Burke, G. Claxton, and P. R. Sparrow, "Intuition in organizations: Implications for strategic management,” Long Range Plann., vol. 42, no. 3, pp. 277-297, Jun. 2009.

[2] M. Kets de Vries, "Organizations on the Couch: A clinical perspective on organizational dynamics,” Eur. Manag. J., vol. 22, no. 2, pp. 183-200, Apr. 2004.

[3] F. Bannister and D. Remenyi, "Acts of faith: instinct, value and IT investment decisions,” J. Inf. Technol., vol. 15, no. 3, pp. 231-241, Sep. 2000.

[4] G. Calabretta, G. Gemser, and N. M. Wijnberg, “The Interplay between Intuition and Rationality in Strategic Decision Making: A Paradox Perspective,” Organ. Stud., vol. 38, no. 3-4, pp. 365-401, Apr. 2017.

[5] H. A. Simon, "Making Management Decisions: The Role of Intuition and Emotion,” Acad. Manag. Exec., vol. 1, no. 1, pp. 5764, 1987.

[6] C. Akinci and E. Sadler-Smith, "Intuition in management research: A historical review,” Int. J. Manag. Rev., vol. 14, no. 1, pp. 104 122, Mar. 2012.

[7] N. Khatri and H. Ng, The Role of Intuition in Strategic Decision Making, vol. 53, no. 1. 2000.

[8] S. Elbanna, J. Child, and M. Dayan, “A model of antecedents and consequences of intuition in strategic decision-making: Evidence from Egypt,” Long Range Plann., vol. 46, no. 1-2, pp. 149-176, 2013.

[9] J. W. Dean and M. P. Sharfman, "Procedural rationality in the strategic decision-making process,” J. Manag. Stud., vol. 30, no. 4, pp. 587-610, Jul. 1993.

[10] E. Brynjolfsson and Erik, "The productivity paradox of information technology,” Commun. ACM, vol. 36, no. 12, pp. 66-77, Dec.
1993.

[11] S.-M. Huang, C.-S. Ou, C.-M. Chen, and B. Lin, “An empirical study of relationship between IT investment and firm performance: A resource-based perspective,” Eur. J. Oper. Res., vol. 173, no. 3, pp. 984-999, Sep. 2006.

[12] A. Boonstra, "Structure and analysis of IS decision-making processes,” Eur. J. Inf. Syst., vol. 12, no. 3, pp. 195-209, Sep. 2003.

[13] A. J. G. Silvius, "Does ROI matter? Insights into the true business value of IT,” Electron. J. Inf. Syst. Eval., vol. 9, no. 2, pp. 93-104, 2006.

[14] J. W. Fredrickson and A. L. Iaquinto, "Inertia and Creeping Rationality In Strategic Decision Processes,” Acad. Manag. J., vol. 32, no. 3, pp. 516-542, 1989.

[15] J. H. Snyman and D. V. Drew, "Complex strategic decision processes and firm performance in a hypercompetitive industry," $J$. Am. Acad. Bus., vol. 2, no. 2, pp. 293-298, 2003.

[16] S. Hart and C. Banbury, "How strategy-making processes can make a difference,” Strateg. Manag. J., vol. 15, no. 4, pp. 251-269, May 1994.

[17] J. R. Kimberly, "Organizational size and the structuralist perspective: A review, critique, and proposal,” Adm. Sci. Q., vol. 21, no. 4, p. 571, Dec. 1976.

[18] W. H. DeLone, "Determinants of success for computer usage in small business,” MIS Q., vol. 12, no. 1, p. 51, Mar. 1988.

[19] G. Vintila and E. A. Nenu, An analysis of determinant of corporate financial performance: Evidence from the Bucharest Stock Exchange listed company, vol. 5, no. 3. 2015.

[20] I. Goll and A. M. A. Rasheed, "Rational decision-making and firm performance: the moderating role of the environment," Strateg. Manag. J., vol. 18, no. 7, pp. 583-591, Aug. 1997.

[21] J. W. Fredrickson, "Strategic process research: Questions and recommendations,” Acad. Manag. Rev., vol. 8, no. 4, p. 565, Oct. 1983.

[22] T. Lawton, T. Rajwani, and P. Reinmoeller, "Do you have a survival instinct? Leveraging genetic codes to achieve fit in hostile business environments,” Bus. Horiz., vol. 55, no. 1, pp. 81-91, Jan. 2012.

[23] W. H. Agor, "The logic of intuition: How top executives make important decisions,” Organ. Dyn., vol. 14, no. 3, pp. 5-18, Dec. 1986.

[24] T. Ravichandran and C. Lertwongsatien, "Strategic Implications of Information Systems Resources and Capabilities: A CompetenceBased Model,” in AMCIS 2000 Proceedings, 2000, pp. 1158-1164. 